Louisiana State University

LSU Digital Commons

3-1-2018

\title{
The Mediating Role of Korean Immigrant Mothers' Psychological Well-Being in the Associations between Social Support and Authoritarian Parenting Style
}

\author{
You Jung Seo \\ University of Maryland, Baltimore County \\ Charissa S.L. Cheah \\ University of Maryland, Baltimore County \\ Sevgi Bayram Özdemir \\ Örebro Universitet \\ Craig H. Hart \\ Brigham Young University \\ Christy Y.Y. Leung \\ The University of Chicago Medicine
}

See next page for additional authors

Follow this and additional works at: https://digitalcommons.Isu.edu/biosci_pubs

\section{Recommended Citation}

Seo, Y., Cheah, C., Özdemir, S., Hart, C., Leung, C., \& Sun, S. (2018). The Mediating Role of Korean Immigrant Mothers' Psychological Well-Being in the Associations between Social Support and Authoritarian Parenting Style. Journal of Child and Family Studies, 27 (3), 979-989. https://doi.org/ 10.1007/s10826-017-0936-9 
Authors

You Jung Seo, Charissa S.L. Cheah, Sevgi Bayram Özdemir, Craig H. Hart, Christy Y.Y. Leung, and Shuyan Sun 


\title{
The Mediating Role of Korean Immigrant Mothers' Psychological Well-Being in the Associations between Social Support and Authoritarian Parenting Style
}

\author{
You Jung Seo ${ }^{1}$ - Charissa S. L. Cheah ${ }^{1}$ - Sevgi Bayram Özdemir ${ }^{2}$ Craig H. Hart ${ }^{3}$. \\ Christy Y. Y. Leung ${ }^{4}$ Shuyan Sun ${ }^{1}$
}

Published online: 10 November 2017

(C) Springer Science+Business Media, LLC 2017

\begin{abstract}
We examined the mediating role of Korean immigrant mothers' psychological well-being in the associations between mothers' emotional vs. instrumental support received from their kin, and their authoritarian parenting style with their preschoolers using longitudinal data. First-generation Korean immigrant mothers with preschool-aged children $\left(N=158 ; M_{\text {maternal age }}=36.11\right.$ years, $\mathrm{SD}=3.90 ; \quad M_{\text {child }}$ age $=4.43$ years, $\mathrm{SD}=1.10$ ) residing in Maryland, U.S., participated in three assessment waves. Each assessment wave was 6 months apart. Mothers reported on the amount of perceived emotional and instrumental support they received from their kin, their behavioral acculturation towards the American culture, and their family demographic information at Wave 1, their psychological well-being at Wave 2, and their authoritarian parenting style at Wave 3. The results revealed that higher levels of perceived instrumental support (but not emotional support) received from kin predicted higher levels of maternal psychological well-being 6 months later, which in turn predicted lower levels of reported authoritarian parenting style 6 months later. Our findings highlighted the importance of psychological well-being as a mechanism that explains how instrumental support can impact Korean immigrant mothers' parenting style, and the importance of distinguishing between types of support. Services providing instrumental support (e.g., childcare assistance) for first-generation
\end{abstract}

Charissa S. L. Cheah

ccheah@umbc.edu

1 University of Maryland, Baltimore County, Baltimore, MD, USA

2 Örebro University, Örebro, Sweden

3 Brigham Young University, Provo, UT, USA

4 University of Chicago Medicine, Chicago, IL, USA immigrant mothers, particularly those with smaller or less effective kin networks, appear important to implement.

Keywords Emotional and instrumental support Psychological well-being $\cdot$ Authoritarian parenting style • Korean immigrant mothers

\section{Introduction}

One challenge of migration for many individuals involves the loss of social ties in their home country and the rebuilding of their social support system in the host country (García et al. 2002). For immigrant mothers, a supportive social network can help alleviate adversities that arise in the process of adapting to a new environment, which can have important implications for their parenting (Izzo et al. 2000). Although greater social support has been shown to be associated with less engagement in the authoritarian parenting style among Chinese Canadian immigrant mothers (Su and Hynie 2011), there is a distinct lack of research on mediating processes that may explain this association. Moreover, these processes have not been explored among first-generation Korean immigrant mothers of young children despite the increasing number of Korean families in the U.S. (Zong and Batalova 2014).

Previous empirical studies have suggested that maternal psychological well-being is a potential mediator that can explain the effects of social support on parenting (Lee et al. 2009; Simons et al. 1993). Among Korean immigrants in the U.S., greater perceived social support was found to be positively associated with more positive psychological wellbeing (Shin et al. 2007). In addition, psychologically well- 
adjusted Korean immigrant mothers have been found to engage in more positive parenting behaviors (Kim 2013). However, the following limitations exist in the literature. First, although the influence of social support on psychological well-being and parenting appear to depend on the forms of support provided (e.g., emotional vs. instrumental support), the unique effects of specific forms of support have not been examined. Second, the effects of support received from kin have not been explored among Korean immigrant mothers who are known to maintain strong kinship networks in the U.S. (Min 2006). Third, most examinations of the effects of support on parenting have utilized cross-sectional data, which preclude understanding of the effects of social support over time. Last, there is great need to examine Korean immigrant mothers' parenting with preschoolers because parenting during the preschool years is associated with later school adjustment, academic achievement, and social success (Gibson-Davis and Grassman-Pines 2010; Oades-Sese et al. 2011).

Korean immigrants are known to maintain strong kinship networks in the U.S. (Min 2006). Kinship refers to social relationships among individuals related by blood or marriage (Dykstra 2009). These relationships are further divided into immediate family formed through lineal relationships and extended family formed through collateral relationships (Dykstra 2009; Johnson 2000). They tend to live within close proximity to their kin and keep in contact with these members in their network more than once a week (Kim and Grant 1997). If the kin members of migrants are already settled at the place of destination, ties among these families tend to be intensified because they are important sources of aid and support for migrants' successful adaptation in the new settlement areas (Goldenberg 1977). In fact, kinship support is the most important resource for the settlement and adjustment of first-generation Korean immigrants in the U.S. Kin members provided both financial and nonfinancial assistance, such as babysitting and legal advice, after immigration (Kim and Hurh 1993; Min 1984). Although previous studies have suggested the importance of social support for Korean immigrants' positive functioning in the U.S., no previous study has empirically examined the role of different types of support provided by kin in Korean immigrant mothers' social network in predicting their psychological well-being and parenting.

Past studies have distinguished between two forms of social support: emotional and instrumental support. Emotional support refers to relational interactions with others that provide intimacy, affection, security, and reassurance (MacPhee et al. 1996; McLanahan et al. 1981). In contrast, instrumental support refers to tangible assistance that is received, such as helping with childcare, lending money, and providing care during illness (MacPhee et al. 1996). Each form of support has been found to influence support recipients differently (e.g., Helgeson 2003; Morelli et al. 2015). For instance, instrumental support is most needed when individuals' resources are insufficient to meet their needs (Jacobson 1986). When individuals perceive the situation as controllable (e.g., separation of family members and caring for children), receiving instrumental support facilitates their efforts to resolve the problem (Cutrona and Russell 1990). Moreover, instrumental support is considered to be more acceptable and expected from kin compared to non-kin such as friends or coworkers, with whom more formal relationships are formed (Messeri et al. 1993; Thoits 2011). In contrast, emotional support may be more important than instrumental support if the stressor is uncontrollable, such as being a victim of a crime (Cutrona and Russell 1990).

Previous studies also suggest that cultural variations exist in the forms and sources of social support available to individuals (Kim and McKenry 1998; MacPhee et al. 1996; Turney and Kao 2009). For instance, Anglo parents reported having more emotional support from their friends than Hispanic and American Indian parents, whereas Hispanic caregivers had more available babysitters from their closeknit social networks compared to parents from the other two ethnic groups (MacPhee et al. 1996). Moreover, Turney and Kao (2009) found that Asian immigrant parents reported having more instrumental support from family members than their non-immigrant Asian American counterparts. However, the effects of each form of support on the wellbeing and parenting of Korean immigrant mothers have not been explored.

Korean immigrant parents tend to be characterized as more authoritarian in their parenting style, compared to their European American counterparts (Viden 2001). This preference for the authoritarian parenting style, which is characterized by the endorsement of strict parental control, being less affectionate, and expectations of absolute obedience in children, has been proposed to be due to the influence of traditional Korean familial values of interdependence, hierarchical structure, and family loyalty (Kim et al. 1997; Kim 2005). Supporting this conjecture, a recent study found that traditional Korean disciplinary practices were positively related to the authoritarian parenting style among Korean immigrant mothers. Moreover, higher levels of adherence to their heritage culture were positively associated with the authoritarian parenting style of these mothers (Cho et al. 2013).

Social support, including emotional and instrumental support, has been found to be related to mothers' parenting behaviors and styles (Andresen and Telleen 1992). Specifically, emotional and instrumental support were associated with less punitive parenting behaviors among Hispanic American mothers who were under stress (Hashima and Amato 1994), and greater perceived neighborhood support 
predicted the use of less physical punishment among Cambodian immigrant mothers in the U.S. (Tajima and Harachi 2010). Moreover, less social support in general was found to be related to Chinese Canadian immigrant mothers' engagement in authoritarian parenting ( $\mathrm{Su}$ and Hynie 2011). Thus, it is important to examine how social support may impact Korean immigrant mothers' parenting, specifically their reported engagement in the authoritarian parenting style.

A model of social support (Aneshensel and Stone 1982) posits that social support has a beneficial effect on well-being (Armstrong et al. 2005). Social support is proposed to have a direct and indirect effect on parenting through parents' psychological well-being (Belsky 1984; Simons et al. 1993; Suzuki 2010). According to a conceptual framework proposed by Armstrong et al. (2005), social support influences parental well-being, which in turn influences parenting. Such processes suggest a temporal aspect of the pathways among social support, psychological well-being, and parenting, but this has not been empirically examined in Korean immigrant samples with longitudinal data. Thus, the examination of the mediating role of Korean immigrant mothers' psychological well-being in these associations, to further understand the mechanisms through which Korean immigrant mothers' social support may impact their parenting, is needed.

Psychological well-being comprises multiple aspects of positive psychological functioning, including self-acceptance, purpose in life, personal growth, autonomy, environmental mastery, and positive relations with others (Ryff 1989). Psychological well-being is especially important for immigrant mothers since they may face acculturation and adjustment challenges (Schnittker 2002). Importantly, psychologically well-adjusted mothers were found to engage in more positive parenting behaviors, such as being more engaged and warm toward their children (Belsky1984; Cheah et al. 2009; MacPhee et al. 1996). Moreover, Chinese immigrant mothers with higher psychological well-being reported using less authoritarian parenting practices ( $\mathrm{Yu}$ et al. 2016). Thus, the potential beneficial effects of positive psychological functioning for decreasing coercive parenting among Korean immigrant mothers should be explored.

Past literature also suggests that perceived social support is an important predictor of psychological well-being (Balaji et al. 2007; Jasinskaja-Lahti et al. 2006). For example, Shin et al. (2007) found that higher levels of perceived social support were positively associated with psychological well-being among Korean immigrants in the U.S. (Shin et al. 2007). Moreover, social support received from family and relatives has been reported to benefit immigrants' psychological well-being (Finch and Vega 2003; García et al. 2002; Jasinskaja-Lahti et al. 2006). Specifically, instrumental support may be more effective for lessening situational burdens or demands directly, compared to emotional support (Min 1984; Thoits 2011). In particular, instrumental support may be more important for Korean immigrant mothers' psychological well-being due to the Korean gender ideology of "wise mother and good wife," which may pressure them to be fully responsible for childcare and housework chores, particularly with their less extensive support networks in the U.S. compared to that in Korea (Kim and Chung 2011). Thus, material and practical aid provided by kin members may be more beneficial for mothers' psychological well-being and parenting than emotional support, particularly among first-generation immigrant mothers with young children who need more tangible assistance such as language translation, financial aid, career-related networking and childcare assistance (Min 1984).

Perceived emotional support from family members, relatives, and friends has been known to positively influence individuals' psychological well-being and reduce emotional distress (Thoits 2011). Immigrant mothers may be at greater risk for emotional problems than non-mother immigrants due to caregiver strain and burden in conjunction with other immigration-related obstacles including racism, discrimination, and unemployment (Browne et al. 2017). Emotional support was found to be the most important form of support in its association with postpartum depression among immigrant mothers from China or Vietnam (Chen et al. 2016). However, no study has examined the relative contributions of instrumental vs. emotional support in their associations with maternal psychological well-being and subsequent parenting.

The aim of the present study was to examine the mediating role of Korean immigrant mothers' psychological well-being in the longitudinal associations between their emotional vs. instrumental support received from kin, and their authoritarian parenting style. Overall, instrumental support from kin members in Korean immigrant mothers' social network (measured at Wave 1) was predicted to be more strongly and positively associated with their psychological well-being (measured at Wave 2, 6 months later), and their parenting style (measured at Wave 3,12 months later) than emotional support received from kin. Moreover, Korean immigrant mothers who received more support from kin were expected to report higher levels of psychological well-being. In turn, higher levels of maternal psychological well-being were expected to be predict less reported use of the authoritarian parenting style.

\section{Method}

\section{Participants}

The sample was taken from a larger two-year longitudinal data set, which includes four assessment waves. In the 
present study, we used data from the first, second, and third assessments. At Wave 1, the sample included 158 firstgeneration immigrant mothers $\left(M_{\mathrm{age}}=36.11\right.$ years, $\mathrm{SD}=$ 3.90) from South Korea with preschoolers $\left(M_{\text {age }}=\right.$ 4.43years, $\mathrm{SD}=1.10$ ) residing in Maryland, U.S. Of this sample, 105 mothers responded to the second assessment wave, and 82 mothers responded to all three assessment waves. All mothers were married and most of them (73.8\%) had at least a college degree. The mothers had been in the U.S. for an average of 10.5 years. The families' Hollingshead index ranged from 17 to 66 , with $64.6 \%$ of participants classified as middle-class (i.e., Hollingshead scores were 40 or greater; Hollingshead 1975). Both mothers and fathers were ethnically Korean.

We conducted a logistic regression analysis to examine whether attrition from Wave 1 to Wave 3 was related to the sample characteristics and the study variables $(n=158$ at Wave $1, n=105$ at Wave 2, and $n=82$ at Wave 3). Specifically, we regressed attrition (dropout $=1$, retention $=0$ ) on the demographic characteristics of maternal age, years of U.S. residency, socioeconomic status (SES), and all other study variables at Wave 2 (Nagelkerke $R^{2}=.04$ ) and Wave 3 (Nagelkerke $R^{2}=.13$ ). The results revealed that none of the variables significantly predicted attrition, indicating that attrition was unrelated to these background characteristics.

\section{Procedures}

Participants were recruited from Asian grocery stores, Korean churches, preschools, and public libraries in Maryland. With the permission of appropriate personnel from each recruiting site, an information session was hosted to provide mothers with opportunities to ask questions and sign up to participate. A phone screening was initially conducted with mothers who expressed interest in participating to verify their eligibility, including whether the mother was the primary caregiver of a healthy child between the ages of 3 to 6 years, and that both parents were ethnically Korean. The mothers' preferred language was also identified. After the phone screening, a home visit was scheduled for data collection for Wave 1. During the home visit, bilingual research assistants first reviewed informed consent forms approved by the first author's Institutional Review Board (IRB) with the mothers, and a copy of the consent forms was given to the mothers for their records. Mothers then completed the semi-structured interview and questionnaires in their preferred language. The mothers were assessed again 6 months later at Wave 2, and 6 months after that at Wave 3. Thus, all three Waves were 6 months apart. Each wave was 6 months apart (cf. Chang) because our participants were mothers of young children, and young children develop rapidly within a 6-month period in terms of language, cognitive, and socio-emotional development.
Thus, mothers need to fulfill or be aware of the physical as well as socioemotional and cognitive needs of children as they develop (Bornstein et al. 2010), which could influence mothers' psychological well-being and parenting style. Moreover, we could have potentially missed important developmental changes during this early developmental period if we have implemented a 1-year lag. Therefore, we chose a 6-month interval period because it is sufficient to allow us to test temporal aspects of the pathways among the variables of interest (Lengua et al. 2007) but not so long as to allow for too many changes to occur.

\section{Measures}

All the measures originally available in English were forward- and back-translated into Korean by bilingual researchers in order to ensure that the same meaning was kept in both versions (Peña 2007). All discrepancies were resolved through discussions between translators.

\section{Family demographics information}

The Family Description Measure (FDM; Bornstein 1991) was used to obtain demographic information on mothers' age, years of U.S. residency, parents' occupation and level of education to calculate their socioeconomic status.

\section{Social support}

The Social Network Questionnaire (SNQ; Antonucci 1986) was administered in a semi-interview format to measure social support and social network. The mothers were presented with a hierarchical social mapping diagram of three concentric circles with the word "you" in the center and asked to picture themselves in the middle. The mothers were asked to place the members of their social networks into three concentric circles, ranging from very close relationship in the inner circle to less close in the outer circle. Kin was defined as immediate (e.g., spouse, parents, children, grandparents, and siblings) or extended family (e.g., aunts, uncles, cousins, and other family; Levitt et al. 1993). Mothers then answered a set of questions to assess the total amount of perceived emotional support (5 items; e.g., "Are there people who you talk to when you are upset, nervous, or depressed?" and "Are there people who make you feel good about yourself?") and instrumental support (4 items; e.g., "Are there people who give you money when you really need it?" and "Are there people who babysit for you if you want to go out to have fun?") that they received from kin across all levels within their network structure. For each item, the participants were asked to determine the total number of persons who provide such support. The total score was then calculated by the sum of the total number of 
people across the 5 or 4 items (for emotional and instrumental support, respectively) who provided the specific type of support. This measure has been shown to be valid across age, ethnicities, and social classes (Antonucci and Akiyama 1987). In the present sample, Cronbach's $\alpha$ 's $=.84$ and .73 for emotional and instrumental support, respectively. The SNQ data were collected at Wave 1.

\section{Psychological well-being}

The 18-item version of Ryff's Psychological Well-Being Scale (RWBS; Ryff 1995) was used to measure mothers' psychological well-being in terms of their self-acceptance, positive relations with others, autonomy, environmental mastery, purpose in life, and personal growth. The RWBS has been validated among diverse ethnic groups (Ryff 2014), including Korean immigrants (Cheah et al. 2016). Mothers responded to each item on a scale of 1 (strongly disagree) to 7 (strongly agree). Examples of items include: (a) self-acceptance, "I like most aspects of my personality"; (b) positive relations with others, "People would describe me as a giving person, willing to share my time with others"; (c) autonomy, "I judge myself by what I think is important, not by what others think is important"; (d) environmental mastery, "I am quite good at mastering the many responsibilities of my daily life"; (e) purpose in life, "Some people wander aimlessly through life, but I am not one of them"; and (f) personal growth, "For me, life has been a continuous process of learning, changing, and growth" (Ryff 1989). An overall well-being composite score was created by summing across all items. Cronbach's alpha for the overall composite in the present study was .79. The RWBS data were collected at Wave 2 .

\section{Authoritarian parenting style}

A modified version of Parenting Styles Dimensions Questionnaire (PSDQ; Robinson et al. 2001; Wu et al. 2002) was used to assess mothers' authoritarian parenting style. This measure has been validated in a Korean immigrant sample (Shin et al. 2010). The authoritarian parenting style subscale is comprised of: (a) physical coercion (5 items; e.g., "I guide my child by punishment more than by reason"); (b) verbal hostility (3 items; e.g., "I yell or shout when my child misbehaves"); and (c) non-reasoning/punitive (3 items; e.g., "I punish by taking privileges away from my child with little if any explanations"). Mothers rated the frequency of their parenting behaviors described in each item on a scale of 1 (never) to 5 (always). The Cronbach's alpha for the authoritarian parenting style subscale was .90 for the present sample. The PSDQ data were gathered at Wave 3.

\section{Acculturation}

In order to control for the effects of maternal acculturation, the Cultural and Social Acculturation Scale (CSAS; Lee 1996) was used to measure mothers' behavioral acculturation towards the mainstream (American) culture in areas of social activities, language proficiency, and lifestyle. This measure has been validated in a Korean immigrant sample (Shin et al. 2010). Sample items include, "How well do you speak in English?", and "How often do you watch TV in English?" with scales ranging from 1 (e.g., "Almost never," "Extremely poor," or "Not at all") to 5 (e.g., "More than once a week," "Extremely well," or "Very much"). The 11 items were summed. Higher score indicates higher level of behavioral acculturation towards the mainstream culture. In the present study, the Cronbach's alpha coefficient was $\alpha$ $=.85$. The CSAS data were gathered at Wave 1 .

\section{Data Analyses}

Missing values were handled using full information maximum likelihood (FIML) through Mplus (Muthén and Muthén 1998-2012) after finding no patterns in the missing data using Little's MCAR test, $\chi^{2}(34)=26.68, p=.81$. The FIML procedure has been found to produce approximately unbiased parameter estimates, particularly at small sample sizes $(N=100$; Enders and Bandalos 2001).

Path analysis was performed using Mplus (Muthén and Muthén 1998-2012) to explore the model fit and to examine direct and indirect effects among the variables. To test for the significance of the indirect effects, $p$-values and confidence intervals were estimated using bootstrapping methods with 5000 replicates and bias-corrected confidence intervals because the distribution of indirect effect coefficients usually violates normality assumption (Preacher and Hayes 2008). The overall model fit was evaluated using the following goodness-of-fit indices: A chi-square test of model fit, root mean square error of approximation (RMSEA), comparative fit index (CFI), and standardized root mean square residual (SRMR). Statistically non-significant $\chi^{2}$ value suggests a good model fit, RMSEA value below .08 and CFI value above .90 indicate acceptable model fit. CFI value greater than .95 , RMSEA value less than .05, and SRMR value less than .08 are all considered good fit (Bollen 1989; $\mathrm{Hu}$ and Bentler 1999).

\section{Results}

Correlations among the main study variables are presented in Table 1. Overall, greater emotional and instrumental supports received from kin were positively and significantly 
correlated with maternal psychological well-being. In addition, maternal psychological well-being was negatively correlated with authoritarian parenting style. Emotional and instrumental supports received from kin were not significantly correlated with authoritarian parenting style.

A path model was conducted to examine the mediating role of maternal psychological well-being (measured at Wave 2) on the associations between perceived emotional and instrumental social support (measured at Wave 1) and authoritarian parenting style (measured at Wave 3). In this path analysis, we controlled for mothers' behavioral acculturation towards the American culture and parents' SES (Fig. 1). All covariates and exogenous variables were allowed to co-vary except for the covariance between SES and two forms of social support because both covariances were not significant. The goodness-of-fit indices indicated that the model fit the data well $\left(\chi^{2}(25)=3.63, p>.05, \mathrm{CFI}=\right.$ $.96, \quad \mathrm{RMSEA}=.07, \mathrm{SRMR}=.04)$. The RMSEA value indicated an acceptable model fit whereas the indices of $\chi^{2}$, CFI, and SRMR indicated a good fit. Therefore, statistical significances of direct and indirect effects of the model were subsequently examined to reveal the results of hypotheses testing.

Figure 1 shows the estimated unstandardized coefficients for all direct paths. Greater instrumental support received from kin significantly predicted higher levels of maternal psychological well-being $(b=0.43, \mathrm{SE}=0.17, p<.05)$. Also, higher maternal psychological well-being significantly predicted less reported engagement in the authoritarian parenting style $(b=-0.02, \mathrm{SE}=0.01, p$ $<.05)$. Direct effects from the two forms of support received from kin to authoritarian parenting style were not statistically significant.

Indirect effects were examined using a bias-corrected bootstrapping approach. The indirect effect involving emotional support, maternal psychological well-being, and authoritarian parenting style was not statistically significant $(b=0.001, \mathrm{SE}=0.002,95 \%$ CI $[-0.001,0.007])$. However, the indirect effect of maternal psychological wellbeing in the association between instrumental support received from kin and their authoritarian parenting style was statistically significant $(b=-0.008, \quad \mathrm{SE}=0.004, \quad 95 \%$ $[-0.019,-0.002])$. That is, higher levels of perceived instrumental support received from kin was related to higher levels of maternal psychological well-being, which in turn was related to lower levels of reported authoritarian parenting style.

\section{Discussion}

The present study examined the mediating role of Korean immigrant mothers' psychological well-being in the associations between their emotional vs. instrumental support received from their kin and their reported engagement in the authoritarian parenting style 12 months later. Our correlational results revealed that both instrumental and emotional support received from kin were positively correlated with maternal psychological well-being 6 months later. However, when both forms of support were examined in the same model, only instrumental support predicted positive psychological well-being. Specifically, Korean immigrant mothers who received more instrumental support from their kin reported higher levels of psychological well-being 6 months later.

Instrumental support received from kin had greater effects on Korean immigrant mothers' psychological wellbeing than emotional support. Korean immigrants' familycentered social support systems are maintained through cultural values that emphasize strong feelings of interdependence within the kinship network (Kim et al. 2006). For first-generation Korean immigrants, the challenges of immigration may require more tangible assistance such as language translation, financial aid, career-related

Table 1 Correlations among the Main Variables

\begin{tabular}{|c|c|c|c|c|c|c|}
\hline & 1 & 2 & 3 & 4 & 5 & 6 \\
\hline 1. Emotional support received from kin at $\mathrm{W} 1$ & - & & & & & \\
\hline 2. Instrumental support received from kin at $\mathrm{W} 1$ & $.73 * *$ & - & & & & \\
\hline 3. Psychological well-being at $\mathrm{W} 2$ & $.24 *$ & $.36^{* *}$ & - & & & \\
\hline 4. Authoritarian parenting style at W3 & .04 & -.00 & $-.33 * *$ & - & & \\
\hline 5. Behavioral acculturation towards mainstream culture at $\mathrm{W} 1$ & $.30 * *$ & $.31 * *$ & $.48^{* *}$ & -.15 & - & \\
\hline 6. Socioeconomic status at $\mathrm{W} 1$ & .09 & $.17 *$ & $.21 *$ & .15 & $.31 * *$ & - \\
\hline Mean & 24 & 10.96 & 89.89 & 1.84 & 32.05 & 48.78 \\
\hline Standard deviation & 13.96 & 6.97 & 11.16 & 0.55 & 8.54 & 12.68 \\
\hline Ranges & $0-77$ & $0-36$ & 64-117 & $1-4.38$ & $13-52$ & $17-66$ \\
\hline
\end{tabular}

$* p<.05 ; * * p<.01$

Note: W1, W2, and W3 refer to Wave 1, Wave 2, and Wave 3, respectively 
Fig. 1 Path model with unstandardized coefficients. Note: Numbers in parentheses indicate standard errors. $* p<.05 . * * * p<.001$
SOCIAL SUPPORT, PSYCHOLOGICAL WELL-BEING, AND PARENTING

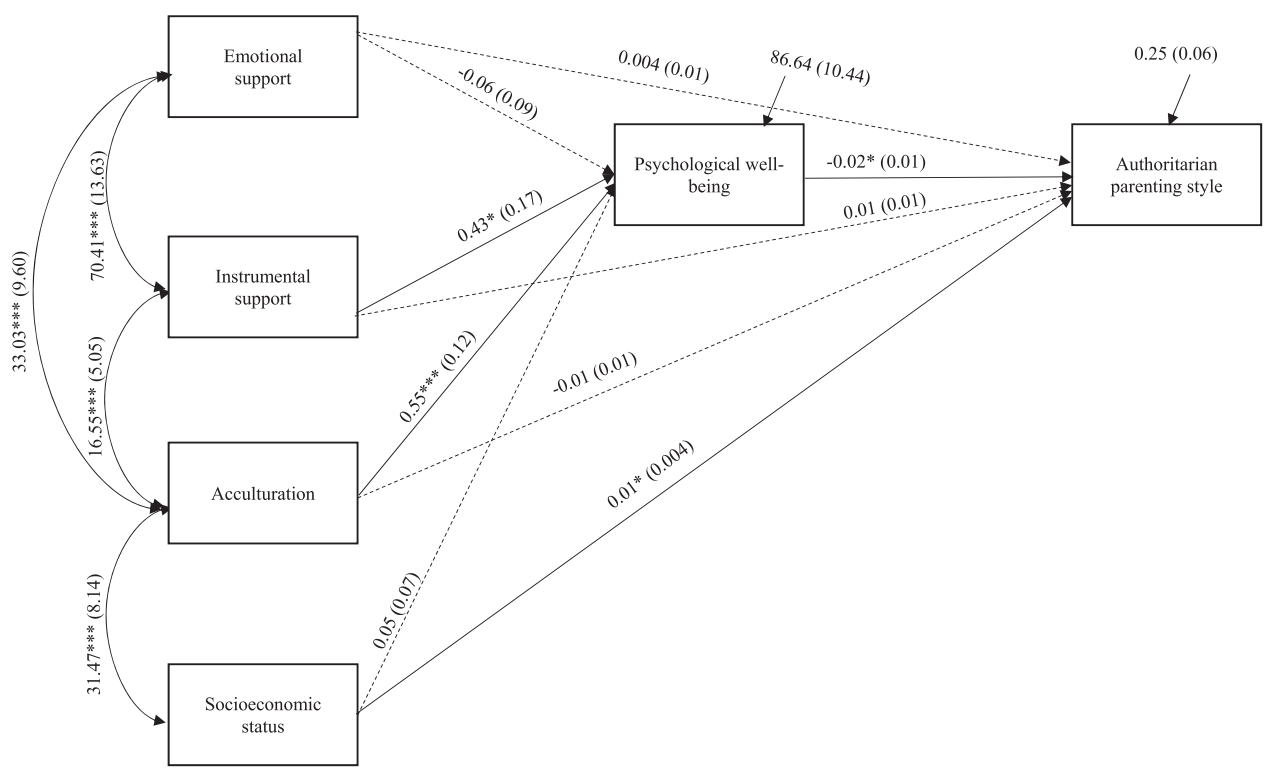

networking, and childcare assistance. Such needs may be particularly salient for immigrant mothers with young children. These mothers may rely primarily on family and relatives to offer active coping assistance as receiving instrumental support from these sources is considered more appropriate than from other sources (Messeri et al. 1993).

The Korean immigrant families in our sample were generally of middle-class socioeconomic status. However, $39 \%$ of these mothers were employed. Previous research has found that when Korean immigrant mothers do not make an income contribution to the family finances, they are restricted in their ability to spend money without their husbands' permission, and tend to have a little discrete money that they control for their own interests (Lim 1997). Thus, perceived tangible support may then increase a sense of financial security that contributes to immigrants' wellbeing (Yoon and Lee 2010). Moreover, two items from the instrumental support scale that we utilized pertained to childcare assistance. Childcare assistance from a grandmother or other relatives may be perceived to be the most trust-worthy, reliable and valuable type of support sought by both non-employed and employed first generation Korean immigrant mothers of young children, as kin-provided child care has been traditionally and widely practiced in Korean society (Lee and Bauer 2013). Thus, the perceived childcare support provided by kin would likely enhance first-generation Korean immigrant mothers' well-being.

Finally, one item from the instrumental support scale asked about sources of care for the mother herself when she is sick. A previous qualitative study found that firstgeneration Korean Americans' primary source of healthrelated help and advice came from their relatives (Kim et al.
2015). These findings reflect the concept of Korean familism that views kin as the only group on which one can unconditionally rely and trust (Lee and Bauer 2013). However, in terms of psychological and emotional matters, first-generation Korean immigrant mothers may be more likely to avoid or be less inclined to discuss such issues with their kin because controlling one's emotions is considered a virtue reflecting good character that promotes the maintenance of cohesion within the group in collectivistic cultures (Safdar et al. 2009; Uba 1994). In addition, when examined together, instrumental support may play a more significant role in first-generation Korean immigrant mothers' well-being than emotional support because immigrant societies are fundamentally embedded with the mindset of achieving the American dream through financial success and making a better living for their children and for themselves (Hong and Hong 1996; Park 1998). Such goals are likely prioritized over socio-emotional needs for firstgeneration immigrants. Therefore, instrumental support to support these goals would likely have a greater perceived significance than emotional support for this population. One caveat from the conclusion regarding the positive effects of instrumental support on maternal psychological well-being is that the effects likely vary depending on the specific kin members providing the support (e.g., spouse, parent, or sibling) or the particular type of instrumental support (e.g., financial support vs. childcare assistance), which should be explored in future research.

According to the task-specific model, individuals prefer help from different sources of support (e.g., kin vs. friends) depending upon the nature of the task and service (Messeri et al. 1993). Individuals prefer kin for financial assistance 
(Hanlon 1982), temporary child care (Hanlon 1982; Litwak and Szelenyi 1969), and help with household chores (Litwak 1985) because these tasks require caregivers with longterm commitment, which is characteristically shared by kin (Messeri et al. 1993). The aid from kin may be even more salient among Korean immigrant mothers who are characterized as having a strong kinship network in the U.S. Instrumental support from kin may increase Korean immigrant mothers' psychological well-being by promoting their capacity to effectively manage the challenges of navigating the new environment and reduce situational demands (Thoits 2011). In contrast, emotional support from kin may be relatively less effective in promoting well-being because kin may devote more attention to problem-solving by providing material and practical aid to alleviate their loved one's distress as quickly as possible (Thoits 2011). Moreover, sharing emotional and personal distress with family is considered less culturally appropriate in Asian cultures compared to Western cultures because emotional distress may risk undermining harmony within family relationships (Taylor et al. 2004).

Importantly, we found that Korean immigrant mothers' psychological well-being fully accounted for the association between their received instrumental support and reported engagement in the authoritarian parenting style. Korean immigrant mothers with higher levels of psychological well-being, which are promoted by the receipt of greater instrumental support from kin, are less likely to engage in punitive tactics, physical coercion, and verbal hostility with their children. Kin-provided instrumental support may allow Korean immigrant mothers to develop a greater sense of environmental mastery and purpose in life. In turn, positive psychological functioning may build immigrant mothers' feelings of confidence in their parenting role (Costigan and Koryzma 2011; Farmer and Lee 2011). Mothers with more psychological resources were less likely to engage in coercive parenting practices that focus on obtaining child compliance 6 months later.

\section{Limitations}

Several limitations of this study should be noted. First, the current study only examined Korean immigrants in a specific geographical region (Maryland and Washington D.C. metropolitan area). The Washington D. C. metropolitan area is the third-largest ethnic Korean community in the U.S. and Korean immigrants living in this area tend to be more highly educated (Oh et al. 2014). Thus, generalizations of the findings from this study to Korean immigrants in other regions of the country should be made cautiously. Moreover, we only examined kinship networks. The role of nonkin social support requires exploration, particularly for Korean immigrants in the U.S. who are also proposed to have strong networks through affiliation with Korean ethnic churches and maintain intimate friendship networks with church members both inside and outside the church (Min 1992).

Second, the design of this study was not ideal for examining longitudinal associations since previous levels of each variable were not controlled for in the present investigation (Mitchell and Maxwell 2013). We are therefore cautious about ascribing causation to these relationships. Third, by utilizing only self-report measures, mothers' responses may be influenced by social desirability. Therefore, additional third-person sources of data (e.g., a spouse or friend) regarding support and observational data on parenting should be utilized in future studies. Finally, additional information on the specific sources of support within the kin networks and the different forms of instrumental vs. emotional support would further elucidate the unique functions of these supports. Future studies that overcome these limitations and examine the role of specific source (e.g., spouse vs. parent) and nature of support (e.g., financial aid or childcare) in promoting maternal psychological well-being and positive parenting behaviors are needed.

Despite these limitations, results from this study suggest that Korean immigrant mothers' psychological well-being is an important mediator that explains how instrumental support can impact their parenting style. These findings can inform related future research that focuses on ways to enhance Korean immigrant mothers' psychological wellbeing. Future studies should also consider examining the effects of non-kinship-based social support on psychological well-being during the immigrant settlement process (Simich et al. 2005).

Author Contributions Y.J.S.: Developed the hypotheses, analyzed the data, and wrote the paper. C.S.L.C.: Designed and executed the study and wrote the paper. S.B.O.: Assisted with the data analyses and writing of the study. C.H.H.: Collaborated with the design and writing of the study. C.Y.Y.L.: Assisted with writing of the study. S.S.: Assisted with the data analyses.

Funding This study was funded by the National Institute of Child Health and Human Development (1R03HD052827-01) awarded to Charissa S. L. Cheah, and the Marjorie Pay Hinckley Endowed Chair and the Zina Young Williams Card Professorship at Brigham Young University awarded to Craig H. Hart.

Conflict of Interest The authors declare that they have no competing interests.

Ethical Approval The University of Maryland, Baltimore County provided IRB approval for the study. All procedures performed in this study were in accordance with the ethical standards of the institutional research committee and with the 1964 Helsinki declaration and its later amendments or comparable ethical standards. 
Informed consent Informed consent was obtained from all individual participants included in the study.

\section{References}

Andresen, P. A., \& Telleen, S. L. (1992). The relationship between social support and maternal behaviors and attitudes: A metaanalytic review. American Journal of Community Psychology, 20, 753-774.

Aneshensel, C. S., \& Stone, X. (1982). Stress and depression: A test of the buffering model of social support. Archives General Psychiatry, 39(12), 1392-1396. https://doi.org/10.1001/archpsyc. 1982.04290120028005 .

Antonucci, T. C. (1986). Hierarchical mapping technique. Generations: Journal of the American Society on Aging, 10(4), 10-12.

Antonucci, T. C., \& Akiyama, H. (1987). An examination of sex differences in social support among older men and women. Sex Roles, 17, 737-749. https://doi.org/10.1007/BF00287685.

Armstrong, M. I., Birnie-Lefcovitch, S., \& Ungar, M. T. (2005). Pathways between social support, family well being, quality of parenting, and child resilience: What we know. Journal of Child and Family Studies, 14(2), 269-281. https://doi.org/10.1007/ s10826-005-5054-4.

Balaji, A. B., Claussen, A. H., Smith, D. C., Visser, S. N., Morales, M. J., \& Perou, R. (2007). Social support networks and maternal mental health and well-being. Journal of Women's Health, 16, 1386-1396. https://doi.org/10.1089/jwh.2007.CDC10.

Belsky, J. (1984). The determinants of parenting: A process model. Child Development, 55, 83-96. https://doi.org/10.1111/14678624.ep7405453.

Bluestone, C., \& Tamis-LeMonda, C. S. (1999). Correlates of parenting styles in predominantly working- and middle-class African American mothers. Journal of Marriage and the Family, 61, 881-893.

Bollen, K. A. (1989). Structural equations with latent variables. New York, NY: Wiley. https://doi.org/10.1002/9781118619179

Bornstein, M. H. (1991). Approaches to parenting in culture. In M. H. Bornstein (Ed.), Cultural approaches to parenting (pp. 3-19). Hillsdale, NJ: Erlbaum.

Bornstein, M. H., Cote, L. R., Haynes, M., Hahn, C., \& Park, Y. (2010). Parenting knowledge: Experiential and sociodemographic factors in European American mothers of young children. Developmental Psychology, 46(6), 1677-1693.

Browne, D. T., Kumar, A., Puente-Duran, S., Georgiades, K., Leckie, G., \& Jenkins, J. (2017). Emotional problems among recent immigrants and parenting status: Findings from a national longitudinal study of immigrants in Canada. PLoS ONE, 12, 1-14. https://doi.org/10.1371/ journal.pone.0175023.

Chang, L., Lansford, J. E., Schwartz, D., \& Farver, J. M. (2004). Marital quality, maternal depressed affect, harsh parenting, and child externalizing in Hong Kong Chinese families. International Journal of Behavioral Development, 28(4), 311-318. https://doi. org/10.1080/01650250344000523.

Cheah, C. S. L., Leung, C. Y. Y., Tahseen, M., \& Schultz, D. (2009). Authoritative parenting among immigrant Chinese mothers of preschoolers. Journal of Family Psychology, 23, 311-320. https://doi.org/10.1037/a0015076.

Cheah, C. S. L., Yu, J., Hart, C. H., Bayram Özdemir, S., Sun, S., Zhou, N., et al. (2016). Parenting hassles mediate predictors of Chinese and Korean immigrants' psychologically controlling parenting. Journal of Applied Developmental Psychology, 47, 13-22. https://doi.org/10.1016/j.appdev.2016.09.005.
Chen, H., Hwang, F., Lin, L., Han, K., Lin, C., \& Chen, L. (2016). Depression and social support trajectories during 1 year postpartum among marriage-based immigrant mothers in Taiwan. Archives of Psychiatric Nursing, 30, 350-355. https://doi.org/10. 1016/j.apnu.2015.12.008.

Cho, Y., \& Kim, Y. S. (2010). Acculturation and the family: Core vs. peripheral changes among Korean Americans. Chaeoe Hanin Yon $G u, 21,135-190$.

Cho, Y., Kim, Y. S., Kim, S. Y., \& Park, I. K. (2013). Is Asian American parenting controlling and harsh? Empirical testing of relationships between Korean American and Western parenting measures. Asian American Journal of Psychology, 4, 19-29. https://doi.org/10.1037/a0031220.

Costigan, C. L., \& Koryzma, C. M. (2011). Acculturation and adjustment among immigrant Chinese parents: Mediating role of parenting efficacy. Journal of Counseling Psychology, 58, 183-196. https://doi.org/10.1037/a0021696.

Cutrona, C. E., \& Russell, D. (1990). Type of social support and specific stress: Toward a theory of optimal matching. In I. G. Sarason, B. R. Sarason \& G. R. Pierce (Eds.), Social Support: An interactional view (pp. 319-366). New York: Wiley.

Dykstra, P. A. (2009). Kin relationships. In H. T. Reis \& S. Sprecher (Eds.), Encyclopedia of human relationships (pp. 951-954). Thousand Oaks, CA: Sage.

Enders, C. K., \& Bandalos, D. L. (2001). The relative performance of full information maximum likelihood estimation for missing data in structural equation models. Structural Equation Modeling, 8, 430-457.

Farmer, A. Y., \& Lee, S. K. (2011). The effects of parenting stress, perceived mastery, and maternal depression on parent-child interaction. Journal of Social Service Research, 37, 516-525. https://doi.org/10.1080/01488376.2011.607367.

Finch, B. K., \& Vega, W. A. (2003). Acculturation stress, social support, and self-rated health among Latinos in California. Journal of Immigrant Health, 5, 109-117. https://doi.org/10. 1023/A:1023987717921.

García, M. F., Ramírez, M. G., \& Jariego, I. M. (2002). Social support and locus of control as predictors of psychological well-being in Moroccan and Peruvian immigrant women in Spain. International Journal of Intercultural Relations, 26, 287-310. https://doi.org/10.1016/S0147-1767(02)00005-6.

Gibson-Davis, C. M., \& Grassman-Pines, A. (2010). Early childhood family structure and mother-child interactions: variation by race and ethnicity. Developmental Psychology, 46, 151-164. https:// doi.org/10.1037/a0017410.

Goldenberg, S. (1977). Kinship and ethnicity viewed as adaptive responses to location in the opportunity structure. Journal of Comparative Family Studies, 8, 149-165.

Hashima, P. Y., \& Amato, P. R. (1994). Poverty, social support, and parental behavior. Child Development, 65, 394-403. https://doi. org/10.1111/j.1467-8624.1994.tb00758.x.

Hanlon, M. D. (1982). Primary group assistance during unemployment. Human Organizations, 41, 156-161.

Helgeson, V. S. (2003). Social support and quality of life. Quality of Life Research, 12, 25-31.

Hollingshead, A. B. (1975). Four-factor index of social status. Unpublished manuscript, Yale University.

Hong, J. J., \& Hong, S. (1996). The Korean American family: Assimilation and its toll on the first and second generation relationship. Retrieved from http://www.eric.ed.gov.

Hu, L., \& Bentler, P. M. (1999). Cutoff criteria for fit indexes in covariance structure analysis: Conventional criteria versus new alternatives. Structural Equation Modeling, 6(1), 1-55. https:// doi.org/10.1080/10705519909540118.

Izzo, C., Weiss, L., Shanahan, T., \& Rodriguez-Brown, F. (2000). Parental Self-Efficacy and Social Support as Predictors of 
Parenting Practices and Children's Socioemotional Adjustment in Mexican Immigrant Families. Journal of Prevention \& Intervention Community, 20, 197-213. https://doi.org/10.1300/ J005v20n01_13.

Jacobson, D. E. (1986). Types and timing of social support. Journal of Health and Social Behavior, 27, 250-264.

Jang, Y., \& Chiriboga, D. A. (2010). Living in a different world: Acculturative stress among Korean American elders. Journal of Gerontology: Psychological Science, 65B, 14-21. https://doi.org/ 10.1093/geronb/gbp019.

Jasinskaja-Lahti, I., Liebkind, K., Jaakkola, M., \& Reuter, A. (2006). Perceived discrimination, social support networks, and psychological well-being among three immigrant groups. Journal of Cross-cultural Psychology, 37, 293-311. https://doi.org/10.1177/ 0022022106286925.

Johnson, C. L. (2000). Perspectives on American kinship in the later 1990s. Journal of Marriage and the Family, 62, 623-639. https:// doi.org/10.1111/j.1741-3737.2000.00623.x.

Kim, E. (2005). Cultivating Korean American ethnicity through parenting. In H. Kim (Ed.), Korean American identities: A look forward (pp. 125-137). Seattle, WA: The Seattle-Washington State Korean American Association.

Kim, E. (2013). Korean American parental depressive symptoms and children's mental health: The mediating role of parental acceptance-rejection. Journal of Pediatric Nursing, 28, 37-47. https://doi.org/10.1016/j.pedn.2012.04.004.

Kim, H. K., \& McKenry, P. C. (1998). Social networks and support: A comparison of African Americans, Asian Americans, Caucasians, and Hispanics. Journal of Comparative Family Studies, 29, 313-334.

Kim, I. J., Kim, L. I. C., \& Kelly, J. G. (2006). Developing cultural competence in working with Korean immigrant families. Journal of Community Psychology, 34, 149-165. https://doi.org/10.1002/ jcop.20093.

Kim, K. C., \& Hurh, W. M. (1993). Beyond assimilation and pluralism: Syncretic sociocultural adaptation of Korean immigrants in the US. Ethnic \& Racial Studies, 16, 696-713. https://doi.org/10. 1080/01419870.1993.9993804.

Kim, K. K., \& Chung, J. (2011). The role of Korean fathers: A study of Korean fathering practices in the United States. International Journal of Child Care and Education Policy, 5, 47-55. https:// doi.org/10.1007/2288-6729-5-2-47.

Kim, W., Kreps, G. L., \& Shin, C. (2015). The role of social support and social networks in health information-seeking behavior among Korean Americans: A qualitative study. International Journal for Equity in Health, 14, 1-10. https://doi.org/10.1186/ s12939-015-0169-8.

Kim, W. J., Kim, L. I., \& Rue, D. S. (1997). Korean American children. In G. Johnson-Powell \& J. Yamamoto (Eds.), Transcultural Child Development: Psychological Assessment and Treatment (pp. 183-207). New York: Wiley.

Kim, Y., \& Grant, D. (1997). Immigration patterns, social support, and adaptation among Korean immigrant women and Korean American women. Cultural Diversity and Mental Health, 3, 235-245. https://doi.org/10.1037/1099-9809.3.4.235.

Lee, B. K. (1996). When East meets West: Acculturation and socialemotional adjustment in Canadian-Chinese adolescents (Unpublished doctoral dissertation). University of Western Ontario, Canada.

Lee, C., Anderson, J. R., Horowitz, J. S., \& August, G. J. (2009). Family income and parenting: The role of parental depression and social support. Family Relations, 58, 417-430. https://doi.org/10. 1111/j.1741-3729.2009.00563.x.

Lee, J., \& Bauer, J. W. (2013). Motivations for providing and utilizing child care by grandmothers in South Korea. Journal of Marriage and Family, 75, 381-402.
Lengua, L. J., Honorado, E., \& Bush, N. R. (2007). Contextual risk and parenting as predictors of effortful control and social competence in preschool children. Journal of Applied Developmental Psychology, 28, 40-55. https://doi.org/10.1016/j.appdev.2006.10. 001.

Levitt, M. J., Weber, R. A., \& Guacci, N. (1993). Convoys of social support: An intergenerational analysis. Psychological Aging, 8, 323-326. https://doi.org/10.1037/0882-7974.8.3.323.

Lim, I. (1997). Korean immigrant women's challenge to gender inequality at home: The interplay of economic resources, gender, and family. Gender and Society, 11, 31-51. https://doi.org/10. 1111/jomf.12014.

Litwak, E. (1985). Helping the elderly: The complementary roles of informal networks and formal systems. New York: Guilford Press.

Litwak, E., \& Szelenyi, I. (1969). Primary group structures and their functions: Kin, neighbors, and friends. American Sociological Review, 34, 465-481.

MacPhee, D., Fritz, J., \& Miller-Heyl, J. (1996). Ethnic variations in personal social networks and parenting. Child Development, 67, 3278-3295. https://doi.org/10.1111/1467-8624.ep9706244860.

McLanahan, S. S., Wedemeyer, N. V., \& Adelberg, T. (1981). Network structure, social support, and psychological well-being in the single-parent family. Journal of Marriage and the Family, 43, 601-612. https://doi.org/10.2307/351761.

Messeri, P., Silverstein, M., \& Litwak, E. (1993). Choosing optimal support groups: A review and reformulation. Journal of Health and Social Behavior, 34, 122-137.

Mitchell, M. A., \& Maxwell, S. E. (2013). A comparison of the crosssectional and sequential designs when assessing longitudinal mediation. Multivariate Behavioral Research, 48(3), 301-339.

Min, P. G. (1984). An exploratory study of kin ties among Korean immigrant families in Atlanta. Journal of Comparative Family Studies, 15, 59-75.

Min, P. G. (1992). The structure and social functions of Korean immigrant churches in the United States. The International Migration Review, 26, 1370-1394. https://doi.org/10.2307/ 2546887.

Min, P. G. (2006). Korean Americans. In P. G. Min (Ed.), Asian Americans: Contemporary trends and issues (pp. 230-261). Thousand Oaks, CA: Pine Forge Press.

Morelli, S. A., Lee, I. A., Arnn, M. E., \& Zaki, J. (2015). Emotional and instrumental support provision interact to predict well-being. Emotion (Washington, D.C.), 15, 484-493. https://doi.org/10. 1037/emo0000084.

Muthén, L. K., \& Muthén, B. O. (1998-2012). Mplus user's guide (7th ed.). Los Angeles, CA: Author.

Oades-Sese, G. V., Esquivel, G. B., Kaliski, P. K., \& Maniatis, L. (2011). A longitudinal study of the social and academic competence of economically disadvantaged bilingual preschool children. Developmental Psychology, 47, 747-764. https://doi.org/10. 1037/a0021380.

Oh, K. M., Zhou, Q., Kreps, G., \& Kim, W. (2014). The influences of immigration on health information seeking behaviors among Korean Americans and Native Koreans. Health Education \& Behavior, 41, 173-185. https://doi.org/10.1177/10901981134 96789.

Park, K. (1998). The Korean American dream: Immigrants and small business in New York City. New York: Cornell University Press.

Peña, E. D. (2007). Lost in translation: Methodological considerations in cross-cultural research. Child Development, 78, 1255-1264. https://doi.org/10.1111/j.1467-8624.2007.01064.x.

Preacher, K. J., \& Hayes, A. F. (2008). Contemporary approaches to assessing mediation in communication research. In A. F. Hayes, M. D. Slater, L. B. Snyder, A. F. Hayes, M. D. Slater, L. B. Snyder (Eds.), The Sage sourcebook of advanced data analysis methods for 
communication research (pp. 13-54). Thousand Oaks, CA: Sage. Publications, Inc. https://doi.org/10.4135/9781452272054.n2.

Robinson, C. C., Mandleco, B., Olsen, S. F., \& Hart, C. H. (2001). The Parenting Styles and Dimensions Questionnaire (PSDQ. In B. F. Perlmutter, J. Touliatos \& G. W. Holden (Eds.), Handbook of family measurement techniques: Vol. 3. Instruments \& index (pp. 319-321). Thousand Oaks: Sage.

Ryff, C. D. (1989). Happiness is everything, or is it? Explorations on the meaning of psychological wellbeing. Journal of Personality and Social Psychology, 57, 1069-1081. https://doi.org/10.1037/ 0022-3514.57.6.1069.

Ryff, C. D. (1995). Psychological well-being in adult life. Current Directions in Psychological Science, 4, 99-104.

Ryff, C. D. (2014). Psychological well-being revisited: Advances in science and practice. Psychotherapy and Psychosomatics, 83, 10-28. https://doi.org/10.1159/000353263.

Safdar, S., Friedlmeier, W., Matsumoto, D., Yoo, S. H., Kwantes, C. T., \& Kakai, H. (2009). Variations of emotional display rules within and across cultures: a comparison between Canada, USA, and Japan. Canadian Journal of Behavioral Science, 41, 1-10. https://doi.org/10.1037/a0014387.

Schnittker, J. (2002). Acculturation in context: The self-esteem of Chinese immigrants. Social Psychological Quarterly, 65, 56-76. https://doi.org/10.2307/3090168.

Shin, H. S., Han, H., \& Kim, M. T. (2007). Predictors of psychological well-being amongst Korean immigrants to the United States: A structure interview survey. International Journal of Nursing Studies, 44, 415-426. https://doi.org/10.1016/j.ijnurstu.2006.04. 007.

Shin, J., Bayram-Ozdemir, S., Lee, J., \& Cheah, C. S. L. (2010). The parenting practices and child outcomes of Korean immigrant mothers with different acculturative strategies. Korean Journal of Child Studies, 31, 1-17.

Simich, L., Beiser, M., Stewart, M., \& Mwakarimba, E. (2005). Providing social support for immigrants and refugees in Canada: Challenges and directions. Journal of Immigrant Health, 7, 259-268.

Simons, R. L., Lorenz, F. O., Wu, C., \& Conger, R. D. (1993). Social network and marital support as mediators and moderators of the impact of stress and depression on parental behavior. Developmental Psychology, 29, 368-381. https://doi.org/10.1037/00121649.29.2.368

Su, C., \& Hynie, M. (2011). Effects of life stress, social support, and cultural norms on parenting styles among Mainland Chinese,
European Canadian, and Chinese Canadian immigrant mothers. Journal of Cross-cultural Psychology, 42, 944-962.

Suzuki, S. (2010). The effects of marital support, social network support, and parenting sress on parenting: Self-efficacy among mothers of young children in Japan. Journal of Early Childhood Research, 8, 40-66. https://doi.org/10.1177/1476718X09345506.

Tajima, E. A., \& Harachi, T. W. (2010). Parenting beliefs and physical discipline practices among Southeast Asian immigrants: Parenting in the context of cultural adaptation to the United States. Journal of Cross-cultural Psychology, 41, 212-235. https://doi. org/10.1177/0022022109354469.

Taylor, S. E., Sherman, D. K., Kim, H. S., Jarcho, J., Takagi, K., \& Dunagan, M. S. (2004). Culture and social support: Who seeks it and why? Journal of Personality and Social Psychology, 87, 354-362. https://doi.org/10.1037/0022-3514.87.3.354.

Thoits, P. A. (2011). Mechanism linking social ties and support to physical and mental health. Journal of Health and Social Behavior, 52, 145-161.

Turney, K., \& Kao, G. (2009). Assessing the private safety net: Social support among minority immigrant parents. The Sociological Quarterly, 50, 666-692.

Uba, L. (1994). Asian Americans: Personality patterns, identity, and mental health. New York: Guilford Press.

Viden, P. G. (2001). Parenting attitudes and children's understanding of mind. A comparison of Korean American and AngloAmerican families. Cognitive Development, 16, 793-809. https://doi.org/10.1016/S0885-2014(01)00059-4.

Wu, P., Robinson, C. C., Yang, C., Hart, C. H., Olsen, S. F., Porter, C. L., et al. (2002). Similarities and differences in mothers' parenting of preschoolers in China and the United States. International Journal of Behavioral Development, 26, 481-491. https://doi.org/ 10.1080/01650250143000436.

Yoon, E., \& Lee, R. (2010). Importance of social connectedness as a moderator in Korean immigrants' subjective well-being. Asian American Journal of Psychology, 1, 93-105. https://doi.org/10. 1037/a0019964.

Yu, J., Cheah, C. S. L., \& Calvin, G. (2016). Acculturation, psychological adjustment, and parenting styles of Chinese immigrant mothers in the United States. Cultural Diversity and Ethnic Minority Psychology, 22, 504-516.

Zong, J. \& Batalova, J. (2014). Korean immigrants in the United States. Migration Information Source. Retrieved from http:// www.migrationpolicy.org/article/korean-immigrants-united-states. 